\title{
Measurement of brood patch temperature of British passerines using an infrared thermometer
}

\author{
D. CHARLES DEEMING ${ }^{*}$ and CHRISTOPHER R. DU FEU ${ }^{2}$ \\ 'Department of Biological Sciences, University of Lincoln, Riseholme Park, Lincoln, LN2 2LG, UK and \\ 266 High Street, Beckingham, Nottinghamshire, DN10 4PF, UK
}

Capsule An infrared ear thermometer can be easily used to measure brood patch temperature in passerines caught on the nest or in mist-nets.

Contact incubation in birds involves the transfer of heat energy from the bird's body through the skin into the egg. This process is enhanced by the development of a brood (or incubation) patch on the ventral abdomen, which is characterized by a highly vascularized, oedemic area of skin from which the feathers have been lost (Lea \& Klandorf 2002). Whilst we have a good understanding of the physiological process of brood patch formation (Lea \& Klandorf 2002), there is relatively little information on the process by which heat is transferred. A better understanding of the temperature of the brood patch is important in understanding contact incubation, particularly when avian body temperatures are some $3^{\circ} \mathrm{C}$ higher than the egg developmental temperature. For instance, for the domestic fowl Gallus gallus the brood patch temperature is recorded at $41.0-41.6^{\circ} \mathrm{C}$ (Eycleshymer 1906, Brummermann \& Reinertsen 1991) yet normal embryonic development is only possible between $37.0^{\circ} \mathrm{C}$ and $38.0^{\circ} \mathrm{C}$ (Deeming \& Ferguson 1991). The situation is further complicated by the fact that egg temperature is often very much lower; Rahn (1991) reported an average egg temperature of $35.7^{\circ} \mathrm{C}$ compared with a body temperature of $40.7^{\circ} \mathrm{C}$. Such values confirm that the dynamics of heat exchange are not simple (Turner 1991, 2002).

Data on brood patch temperature (BPT) are rather limited. Drent (1975) reported values for ten species and Rahn (1991) reported values for a further 11 species. Since then brood patch temperatures have been reported for nearly 60 species (D.C. Deeming unpubl. data). The paucity of data is almost certainly

*Correspondence author.

Email: cdeeming@lincoln.ac.uk due to the difficulties in determining accurate values in nests. Typically, thermisters have been used to measure skin temperature on the brood patch (Ward 1990, Brummermann \& Reinertsen 1991). This has meant that larger bird species have been studied in greater detail than passerines. However, body temperature is higher in small birds: passerines have an average body temperature of $42.0^{\circ} \mathrm{C}$ compared with $41.2^{\circ} \mathrm{C}$ for waterfowl (McNab 1966). Two values for passerines presented by Rahn (1991) suggested that BPT $\left(42.4^{\circ} \mathrm{C}\right.$ and $40.6^{\circ} \mathrm{C}$ ) was higher than for large birds (two waterfowl species had BPTs of $38.5^{\circ} \mathrm{C}$ and $37.7^{\circ} \mathrm{C}$ ).

This begs the question of whether BPT is a function of body size. Given the significance of the brood patch in contact incubation, this short report details an attempt to determine whether BPT is higher in passerine species than in larger species. To do so a novel technique was used. Infrared thermometers, which are normally used to determine ear temperatures in humans, are often used to measure eggshell temperature in commercial artificial incubation. This study examined whether this method of measurement could be used in the field to measure BPT in passerines.

Brood patch temperatures were measured using an infrared thermometer (Thermoscan model 4520, Braun Kronbeg, Germany) with a temperature range of $34.0-42.2^{\circ} \mathrm{C}$ and an accuracy of $\pm 0.2^{\circ} \mathrm{C}$. Given the two to three seconds required to obtain a temperature reading, checking the calibration of the unit proved difficult, but eventually it was successfully achieved by measuring the surface temperature of a large object with high thermal inertia, in this case a water-filled Ostrich Struthio camelus egg, maintained in an oven set at an air temperature of $40^{\circ} \mathrm{C}$ and checked with a mercury reference thermometer. 
With the bird in the hand the thermometer's sensor was gently placed and held on the skin of the brood patch in a central position during measurement. This position was located by feeling the posterior end of the keel of the sternum (Fig. 1). Measurement of the temperature in this way is non-intrusive and can be as rapid as other measurements routinely made on birds. Ringers need no additional licence or endorsement in order to measure temperatures in this way.

Two or three readings were taken from each bird, which were then averaged. In some instances the skin temperature was higher than the normal range of the thermometer $\left(42.2^{\circ} \mathrm{C}\right)$. In these instances, temperatures within the measurement range for each bird were averaged. It was appreciated that this potentially caused a lower average temperature, but of 232 measurements only 32 instances (13.8\%) were off the top of the scale ('high'), although such instances were not seen in all species. Only 5\% of 47 measurements for Blue Tits Cyanistes caeruleus were high, although approximately one-third of measurements were high for Common Blackbirds Turdus merula $(n=34)$ and Blackcaps Sylvia atricapilla $(n=18)$. For 11 of the 18 species reported here no high readings were observed. Moreover, for instances where the upper range of the thermometer was exceeded, the previous measurements were all between $41.9^{\circ} \mathrm{C}$ and $42.2^{\circ} \mathrm{C}$.

Brood patches were assessed according to their stage of development as defined on the following scale of

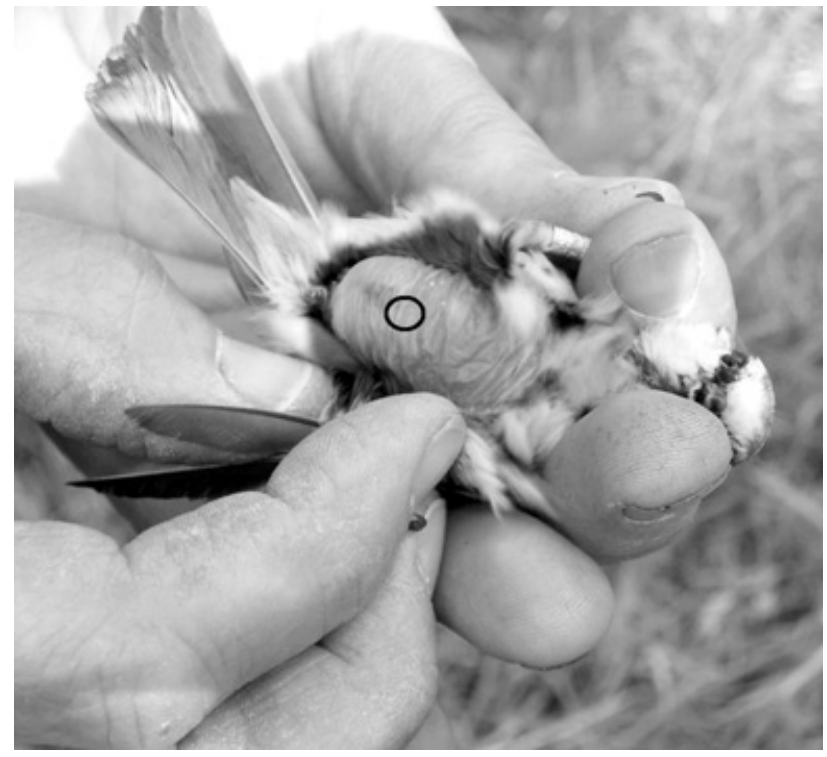

Figure 1. Brood patch of a Blue Tit indicating the position at which temperature was recorded (circled) on a grade 3 brood patch.

codes, as illustrated in Fig. 2 (BTO 2006): 0, absent; 1, starting; 2, well-defined: breast muscle and gut still visible through the skin; 3 , veined and red: the skin of the belly is opaque, thickened or engorged, veined and red with broad, undulating wrinkles; 4 , wrinkled: the skin of the belly has thin wrinkles, engorgement of the skin has gone, but the skin is still stretched, and the breast muscle and gut are visible again through the skin,

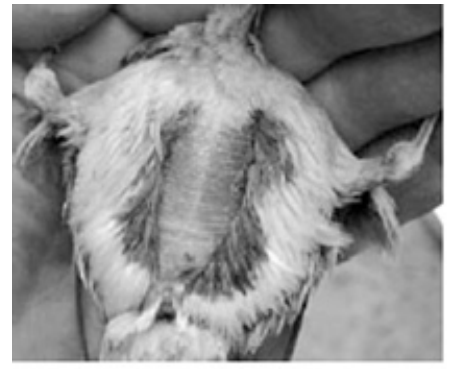

Brood Patch 1 (Graham Austin)

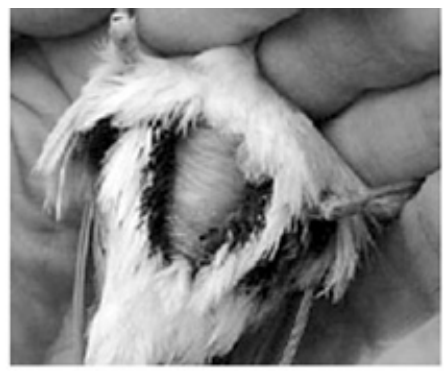

Brood Patch 2 (Graham Austin)

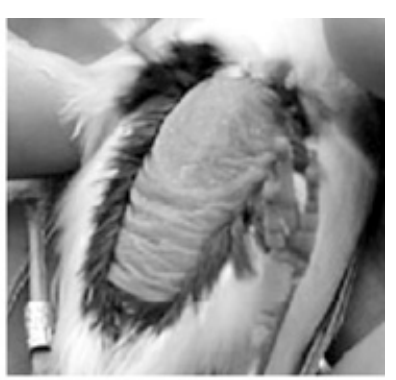

Brood Patch 3 (Jez Blackburn)

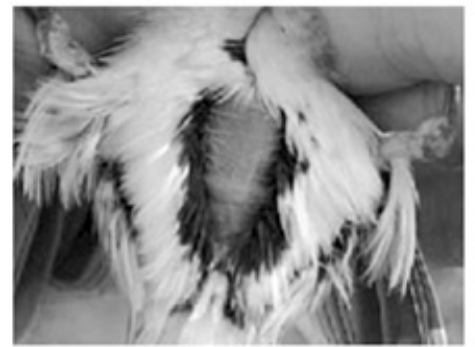

Brood Patch 4 (Graham Austin)

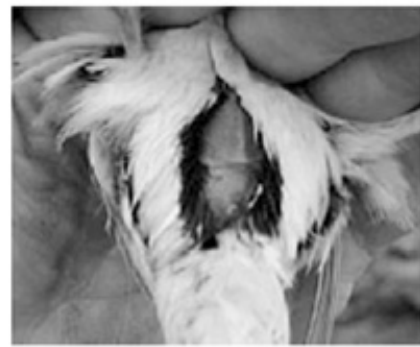

Brood Patch 5 (Graham Austin)

Figure 2. Examples of brood patches on Reed Warblers Acrocephalus scirpaceus at different stages of development (see text). Reproduced with permission of the British Trust for Ornithology. 
growing over; 5, feathering over. Records of brood patch temperature in our study were typically made on birds exhibiting a brood patch of code 2-4 but mainly code 3 .

In the first part of the study female Blue Tits were caught on the nest during routine examination of nestboxes in an area of mixed woodland in England (Treswell Wood, Nottinghamshire), which has been the subject of a long-term study (du Feu \& McMeeking 1991). In the same woodland and at the same time of year, breeding Blue Tits were caught in mist-nets. BPT was recorded for each female bird with an obvious brood patch and BPTs recorded on the nest or in flight were compared using a two-sample $t$-test.

The second part of the study involved recording BPT of any female birds of a variety of species that were caught in mist-nets within Treswell Wood during the same period. The exceptions were data for the Sand Martins Riparia riparia, which were collected from females mist-netted whilst exiting their nest burrows at a site at Scunthorpe, Lincolnshire, and for two male Blackbirds caught in a garden in Beckingham, Nottinghamshire. In all cases data were averaged for each species.

Data for BPT were recorded for Blue Tits caught on the nest and in mist-nets. The BPT of nest-caught birds $\left(41.1 \pm 0.7^{\circ} \mathrm{C}, n=9\right.$, range $\left.=40.1-41.9^{\circ} \mathrm{C}\right)$ was higher than those for mist-netted birds (Table 1) but this was not a significant difference $(t=-1.88, P=0.092, \mathrm{df}=$
9). Data for a further 16 passerine species and one woodpecker species caught in mist-nets are shown in Table 1. In all but four cases the BPTs were above $41.0^{\circ} \mathrm{C}$ and the other values were above $40.0^{\circ} \mathrm{C}$. The ventral skin temperatures of two male blackbirds averaged $38.5^{\circ} \mathrm{C}$, which was almost statistically significantly lower than the BPT of females (see Table 1; Mann-Whitney test, $P=0.056$ ).

The infrared thermometer was easy to use in the field and proved to be a useful tool in recording BPT. One modification of the procedure would be to increase the high range of the sensor to measure the maximum BPT values, and so improve the accuracy of measurements in some species. Hence, this system provides an efficient, non-intrusive and cost-effective method for measuring BPT (and skin temperature) in a variety of bird species. In particular, in situations where the bird can be lifted from a nest without fear of desertion (Kania (1992) lists desertion rates in European species) more data on BPT could be easily recorded.

For Blue Tits there was no difference in BPTs recorded for birds on the nest and for birds caught in mist-nets. This suggests that recording the BPT of incubating birds when they are away from the nest provides meaningful values for BPT in breeding female passerines. However, it is recognized that this conclusion needs validation by monitoring BPTs of the same individuals on, and away from, the nest. The effect of handling time, or time in the mist-net, on BPT is also

Table 1. Average brood patch temperatures (BPT) for birds caught in mist-nets in Treswell Wood.

\begin{tabular}{|c|c|c|c|c|}
\hline Species & Average BPT $\left({ }^{\circ} \mathrm{C}\right)$ & sd & Range $\left({ }^{\circ} \mathrm{C}\right)$ & $n$ \\
\hline Greater Spotted Woodpecker Dendrocops majora & 40.6 & 0.8 & $39.8-41.5$ & 1 \\
\hline Sand Martin Riparia ripariab & 40.3 & 0.9 & $39.6-41.6$ & 4 \\
\hline Winter Wren Troglodytes troglodytes & 41.3 & 0.7 & $40.6-41.9$ & 3 \\
\hline Hedge Accentor Prunella modularis & 41.9 & - & - & 1 \\
\hline European Robin Erithacus rubecula & 41.0 & - & $40.2-41.8$ & 2 \\
\hline Common Blackbird Turdus merula & 41.2 & 0.7 & $39.9-41.8$ & 6 \\
\hline Song Thrush Turdus philomelos & 40.0 & - & - & 1 \\
\hline Blackcap Sylvia atricapilla & 41.1 & 0.6 & $40.3-41.8$ & 4 \\
\hline Spotted Flycatcher Muscicapa striata & 40.9 & - & - & 1 \\
\hline Blue Tit Cyanistes caeruleus & 40.2 & 1.0 & $39.2-41.7$ & 5 \\
\hline Great Tit Parus major & 41.0 & 0.6 & $39.8-41.9$ & 8 \\
\hline Marsh Tit Poecile palustris & 41.3 & - & $40.2-42.2$ & 2 \\
\hline Coal Tit Periparus ater & 40.5 & 1.0 & $39.1-41.7$ & 5 \\
\hline Wood Nuthatch Sitta europea & 41.1 & - & - & 1 \\
\hline Eurasian Treecreeper Certhia familiaris & 41.7 & - & - & 1 \\
\hline Chaffinch Fringilla coelebs & 41.6 & 0.4 & $41.1-42.2$ & 6 \\
\hline European Greenfinch Carduelis chloris & 41.9 & - & $41.9-42.0$ & 2 \\
\hline Common Bullfinch Pyrrhula pyrrhula & 41.1 & - & - & 2 \\
\hline Houbara bustard Chlamydotis undulatac & 39.2 & 0.5 & $38.7-40.1$ & 5 \\
\hline
\end{tabular}

$n$, Number of birds studied. aSingle bird caught on three separate days. birds caught at colony at Scunthorpe. ${ }^{C D}$.C. Deeming pers. obs. 2006. 
unknown but could be investigated. The technique of using an infrared thermometer to measure BPT makes these objectives easy to achieve.

The data presented in Table 1 are comparable to values for BPT recorded for North American passerines (Table 2), which range from $40.3^{\circ} \mathrm{C}$ in Dark Eyed Juncos Junco phaetonotus (Hainsworth \& Voss 2002) to $42.5^{\circ} \mathrm{C}$ in Dusky Flycatchers Emphidonax oberholseri (Morton \& Pereyra 1985). The present study has increased our data on BPT in passerines by 17 species and is the first report of BPT in a woodpecker.

It would seem that passerines are characterized by a higher BPT than birds from a wide range of orders, which have larger body masses (D.C. Deeming unpubl. data 2007). Previous reports show that average BPT for eight species of waterfowl was $39.5^{\circ} \mathrm{C}$ (range $37.7-40.9^{\circ} \mathrm{C}$ ), and for 11 species of shorebird the average $\mathrm{BPT}$ was $37.8^{\circ} \mathrm{C}$ (range $34.9-40.7^{\circ} \mathrm{C}$ ). Using the same infrared thermometer, the BPT of captive Houbara Bustards Chlamydotis undulata recorded immediately after being lifted from their nests was on average lower than that of passerines (Table 1). Hence, it seems that the higher body temperatures recorded for smaller birds (McNab 1966) are reflected in their BPT. Higher BPTs may be related more to the type of bird than to body size per se but more data are needed to confirm this.

Sex differences in skin temperature have been reported in a passerine species. In House Sparrows Passer domesticus, although absolute values were not reported, Bartlett et al. (2005) showed that the ventral skin of incubating females was $2.09^{\circ} \mathrm{C}$ warmer than the dorsal skin, but in male birds the ventral skin was $0.83^{\circ} \mathrm{C}$ cooler than the dorsal skin. In this study male Blackbirds lacking brood patches had a lower ventral skin temperature than females with a brood patch. Whether this is typical for uniparental incubators needs further investigation. The fact that some BPTs recorded in the present study were less than $40^{\circ} \mathrm{C}$ suggests that there is variation between individuals, and perhaps in mist-netted birds the brood patch was not functional because of nest desertion or predation.

It is appreciated that these data could be considered preliminary and our intention is to extend our data set in future breeding seasons. However, it is hoped that the technique described here will encourage other field ornithologists to record BPT in a wider variety of species. This simple technique has generated other questions about brood patch function. For instance, how does the ventral skin temperature change with the development and regression of the brood patch? Future work will record BPT in a variety of situations based on the following protocol:

- record time and date of measurement;

- record weather conditions (e.g. ambient temperature, wind, rain, cloud cover);

- record species and sex;

- record stage of brood patch development (code 3 should be the typical stage of development);

- record three brood patch temperatures in rapid succession at an early stage in processing the bird.

Data collected during these studies will assist in increasing our understanding of the process of heat exchange during contact incubation in birds.

\section{ACKNOWLEDGEMENTS}

We thank Nottinghamshire Wildlife Trust for permission to work within Treswell Wood. We are very grateful to John Clark for his help in the field and for discussions about the technique. Many thanks to John McMeeking and Neil Taylor for their assistance in collecting data. Paul Eady and Glenn Baggott also provided constructive criticism of a previous draft of this manuscript. Many thanks go to the staff of the British Trust for Ornithology, Thetford, for permission to reproduce their photographs.

\section{REFERENCES}

Bartlett, T.L., Mock, D.W. \& Schwagmeyer, P.L. 2005. Division of labor: incubation and biparental care in house sparrows (Passer domesticus). Auk 122: 835-842.

Brummermann, M. \& Reinertsen, R.E. 1991. Adaptation of homeostatic thermoregulation: comparison of incubating and non-

Table 2. Average brood patch temperatures (BPT) reported for Passerines.

\begin{tabular}{lcc}
\hline Species & Average BPT \pm sd $\left({ }^{\circ} \mathrm{C}\right)$ & Reference \\
\hline Dark-eyed Junco Junco phaeton & $40.3 \pm 1.4$ & Hainsworth \& Voss (2002) \\
House Wren Troglodytes aedon & 40.6 & Kendeigh (1963) \\
Mountain White-crowned Sparrow Zonotrichia leucophrys oriantha & 41.8 & Morton (2002) \\
Dusky Flycatcher Emphidonax oberholseri & $41.52 \pm 0.56(1-4$ days) & Morton \& Pereyra (1985)
\end{tabular}

${ }^{a}$ Average measurements during days of incubation indicated. 
incubating Bantam hens. J. Comp. Physiol. B 161: 133-140.

BTO 2006. CES News, March 2006. Available from http://www.bto. org/ringing/ringinfo/ ces/ces_new_index.htm

Deeming, D.C. \& Ferguson, M.W.J. 1991. Physiological effects of incubation temperature on embryonic development in reptiles and birds. In Deeming, D.C. \& Ferguson M.W.J. (eds) Egg Incubation. Its Effects on Embryonic Development in Birds and Reptiles: 147-172. Cambridge University Press, Cambridge.

Drent, R.H. 1975. Incubation. In Farner, D.S. \& King, J.R. (eds) Avian Biology, Vol. 5: 333-420. Academic Press, New York.

Du Feu, C. \& McMeeking, J. 1991. Does constant effort netting estimate juvenile abundance? Ring. Migr. 12: 118-123.

Eycleshymer, A.C. 1906. Some observations and experiments on the natural and artificial incubation of the egg of the common fowl. Biol. Bull. 12: 360-374.

Hainsworth, F.R. \& Voss, M.A. 2002. Intermittent incubation: predictions and tests for time and heat allocations. In Deeming, D.C. (ed.) Avian Incubation: Behaviour, Environment, and Evolution: 223-237. Oxford University Press, Oxford.

Kania, W. 1992. Safety of catching adult European birds at the nest. Ringers' opinions. Ring 14: 5-50.

Kendeigh, S.C. 1963. Thermodynamics of incubation in the house wren, Troglodytes aedon. Proceedings of XIIth International Ornithology Congress, Ithaca: 884-904.
Lea, R.W. \& Klandorf, H. 2002. The brood patch. In Deeming, D.C. (ed.) Avian Incubation: Behaviour, Environment, and Evolution: 100-118. Oxford University Press, Oxford.

McNab, B.K. 1966. An analysis of body temperatures of birds. Condor 68: 47-55.

Morton, M.L. 2002. The Mountain White-crowned Sparrow: migration and reproduction at high altitude. Calif. Stud. Avian Biol. 24.

Morton, M.L. \& Pereyra, M.E. 1985. The regulation of egg temperatures and attentiveness patterns in the dusky flycatcher (Emphidonax oberholseri). Auk 102: 25-37.

Rahn, H. 1991. Why birds lay eggs. In Deeming, D.C. \& Ferguson M.W.J. (eds) Egg Incubation. Its Effects on Embryonic Development in Birds and Reptiles: 345-360. Cambridge University Press, Cambridge.

Turner, J.S. 1991. The thermal energetics of incubated bird eggs. In Deeming, D.C. \& Ferguson M.W.J. (eds) Egg Incubation. Its Effects on Embryonic Development in Birds and Reptiles: 117-146. Cambridge University Press, Cambridge.

Turner, J.S. 2002. Maintenance of egg temperature. In Deeming, D.C. (ed.) Avian Incubation: Behaviour, Environment, and Evolution: 119-142. Oxford University Press, Oxford.

Ward, D. 1990. Incubation temperatures and behaviour of crowned, black-winged, and lesser black-winged plovers. Auk 107: $10-17$.

(MS received 3 April 2007; revised MS accepted 13 July 2007) 